Provided for non-commercial research and education use. Not for reproduction, distribution or commercial use.



This article appeared in a journal published by Elsevier. The attached copy is furnished to the author for internal non-commercial research and education use, including for instruction at the authors institution and sharing with colleagues.

Other uses, including reproduction and distribution, or selling or licensing copies, or posting to personal, institutional or third party websites are prohibited.

In most cases authors are permitted to post their version of the article (e.g. in Word or Tex form) to their personal website or institutional repository. Authors requiring further information regarding Elsevier's archiving and manuscript policies are encouraged to visit:

http://www.elsevier.com/authorsrights 


\title{
Influence of low-density polyethylene addition on coking pressure
}

\author{
S. Melendi ${ }^{1, *}$, C. Barriocanal, R. Alvarez, M.A. Diez \\ Instituto Nacional del Carbón (INCAR), CSIC, Apartado 73, 33080 Oviedo, Spain
}

\section{H I G H L I G H T S}

- Coke production is a viable option to recycle plastics as secondary raw materials.

- Coking pressure rises for low LDPE addition ( $\leqslant 3 \mathrm{wt} . \%$ ); higher amounts reduce pressure.

- LDPE influences the pyrolysis process and the swelling process of the plastic stage.

- A delay in the LDPE degradation is confirmed by DRIFT and SEM.

\section{A R T I C L E I N F O}

\section{Article history:}

Received 9 September 2013

Received in revised form 29 October 2013

Accepted 28 November 2013

Available online 11 December 2013

\section{Keywords:}

Carbonisation

Coking pressure

Semicoke

Tar

\begin{abstract}
A B S T R A C T
Different amounts of low-density polyethylene (LDPE) were added to a bituminous coal used to produce metallurgical coke. The effect of the plastic waste on the carbonization process and more exactly, on the coking pressure were investigated. A movable wall oven at semi-pilot scale was used for measuring coking pressure generated. It was found that coking pressure increases for low LDPE addition levels (1-3 wt.\%); however higher amounts of LDPE reduce coking pressure. To explain this behavior different blends of the coal and the residue were pyrolysed at three different temperatures $\left(450,500\right.$ and $\left.600{ }^{\circ} \mathrm{C}\right)$ in a Gray-King apparatus. The results show that LDPE causes a modification in the pyrolysis process and also influences the swelling process of the plastic stage.

The increase of the coking pressure at low LDPE addition rates is associated with a less permeable coal plastic layer, which prevents the removal of the decomposition products and causes their retention in the semicoke matrix, evolving them in the post-plastic stage. Coking pressure decrease at high LDPE addition rates can be due to the charge shrinkage and the better permeability to the migration of oil components, which suggest a lower interaction between the coal and the LDPE. A delay in the degradation of LDPE is confirmed by the data provided by DRIFT and SEM.
\end{abstract}

(c) 2013 Elsevier Ltd. All rights reserved.

\section{Introduction}

The environmental impact due to waste production, both domestic and industrial, has become a high priority part of environmental policies in developed countries. Even though waste management has undergone a significant evolution in the recent decades, waste recovery continues to be of great importance to achieve sustainable development and compatibility with environmental protection. It has been necessary to allocate time and resources to develop processes to ensure plastic recycling is an economically profitable process, helping to decrease the amount of residue designated to landfill disposal. As a result of recent European legislation for management and recovery of plastic

\footnotetext{
* Corresponding author. Tel.: +44 7412077279.

E-mail address: smelendi@gmail.com (S. Melendi).

1 Present address: Division of Materials, Mechanics and Structures, Faculty of Engineering University of Nottingham, Polymer Composites Group, Nottingham NG7 2RD, United Kingdom.
}

wastes from packaging, the development of new processes for mechanical and chemical recycling and energy recovery are being promoted in order to achieve the recycling objectives.

The use of plastics as secondary raw materials in metallurgical coke production is an environmentally friendly alternative for recycling municipal plastic wastes. These wastes can be added as minor components to the coal that is used as feedstock in this industrial process [1-3]. Depending on the composition of plastic waste, a different effect can be expected on the fluidity of the coal or coal blends, the semicoke structure and the structure and properties of high temperature cokes [3-9]. Previous investigations have shown the addition of plastic wastes induces a decrease in the Gieseler maximum fluidity. The extent of this reduction depends on the amount, structure and thermal behavior of the plastic residue added [5-9]. Polyolefins (LDPE, HDPE and PP) reduce the fluidity development to a lesser degree, while polymers containing aromatic rings in their structure (PS and PET) significantly decrease the fluidity of the coal. The interactions between coal and plastics also cause modifications on the optical structure of the semicokes, 
decreasing the anisotropic development and the size of the anisotropic components [9]. Moreover, certain types of plastic waste such as polyolefins can be incorporated, in small amounts, into typical coking blends as secondary raw materials without notably modifying coke properties. Preliminary results obtained at a semi-industrial scale at INCAR show that a coking coal blend can tolerate up to $3 \mathrm{wt}$.\% of polyethylene waste without any significant deterioration of the coke quality parameters [3]. Although the quality of the coke is maintained or slightly improved when polyolefins are added in small quantities, single polyolefins or wastes rich in them increase the coking pressure during the process, when there are added at a low addition rates, becoming dangerous carbonizations $[10,11]$. The mechanism that generates coking pressure is not well understood. The generation of high coking pressure by some coals is due to the combination of two phenomena; the release and the characteristics of the volatile matter evolved and the ability of gas to escape through the plastic layer. Previous authors have related the internal pressure to several factors; the permeability of the plastic layer [12-14], the emission of volatile matter and the plasticity of the plastic layer [15] and the fissure pattern of the semicoke and the pore structure [16-20].

In order to avoid the negative effects of the polyolefins on the coking pressure, different approaches have been proposed. Possible alternatives include carrying out carbonization at a lower bulk density, subsequently reducing yield and quality of the obtained coke; adjusting the amount of polyolefins in the waste [11] or recycling organic wastes and lubricating oils of different origins by adding these wastes to typical coal blends and plastic waste mixtures [21-23].

To investigate the effects of the amount of low density polyethylene (LDPE) on coal fluidity development, coking pressure generation and the coking pressure mechanism, Gray King pyrolysis was carried out at three different temperatures using a coking coal and its blends with up to $10 \mathrm{wt} . \%$ additions of LDPE. The structure and morphology of the semicokes and the study of obtained tars is a useful way to elucidate the mechanism of interaction between coal and polyethylene in order to explain the effect of the polyolefins on coking pressure. LDPE was chosen as being representative of the polyolefins contained in municipal, agricultural or other different sectors.

\section{Materials and methods}

Previous results using different coals and coal blends have shown that single polyolefins (LDPE, HDPE and PP) increase the pressure exerted against the wall in the course of coking process at low addition rates $[10,11]$. In this work it was decided to use an individual coal instead of a blend in order to isolate the effect of the LDPE on the coking pressure. The coal G has been selected for this study due to its similarity to industrial blends used in the coking industry in terms of volatile matter and fluidity $[21,22]$. Proximate analysis of the coal was performed following the ISO562 and ISO1171 standard procedures for volatile matter and ash content, respectively. The elemental analysis was determined with the aid of a LECO CHN-2000 for C, H and N, a LECO S-144 DR for sulfur and oxygen was estimated by difference. The main characteristics of the single coal $\mathrm{G}$ are presented in Table 1.

Low-density polyethylene (LDPE) from agricultural greenhouse films was selected for this study as it can be taken as representative of polyolefins from other different post-consumer sectors. The nomenclature used in this study is as follows: $G$ is the individual coal, followed by a number corresponding to the addition rate (wt.\%) and followed by the initials of the waste, in this case LDPE.

The coking coal and its mixtures with LDPE were carbonised in a semi-pilot moveable wall oven of $15 \mathrm{~kg}$ capacity (MWO15). The coking time lasted nearly $3 \mathrm{~h}$ with the temperature in the centre
Table 1

Main characteristics of the coal G.

\begin{tabular}{ll}
\hline & Coal G \\
\hline VM (wt.\% db) & 21.2 \\
Ash (wt.\% db) & 9.0 \\
C (wt.\% daf) & 90.6 \\
H (wt.\% daf) & 5.0 \\
N (wt.\% daf) & 1.8 \\
S (wt.\% daf) & 0.6 \\
O (wt.\% daf) & 2.0 \\
Maximum Gieseler fluidity (ddpm) & 423 \\
\hline
\end{tabular}

of the charge reaching a maximum of $950{ }^{\circ} \mathrm{C}$ by the end of the process. The MWO15 is described in detail elsewhere [21].

The thermoplastic properties of the coal and its blends with up to $10 \mathrm{wt}$.\% LDPE were tested in a Gieseler plastometer, using the R.B. Automazione model PL2000 and following the ASTM D 2639 standard procedure. The specific parameters for this test are: (i) the softening temperature at which the coal starts to be fluid (Ts); (ii) the temperature of maximum fluidity reached during the thermal heating $\left(T_{f}\right)$; (iii) the temperature at which the fluid mass resolidifies into a semicoke $\left(T_{r}\right)$; (iv) the plastic or fluid range, which is defined as the difference between the resolidification and softening temperatures $\left(T_{r}-T_{s}\right)$; (v) $F_{\max }$, the maximum fluidity, expressed as dial divisions per minute (ddpm).

Samples of the individual plastic (LDPE) and the bituminous coal $G$ were subjected to thermogravimetric analysis (TGA) in a simultaneous TA instrument SDT2960 analyzer. $10 \mathrm{mg}$ of plastic was heated from room temperature up to $600{ }^{\circ} \mathrm{C}$ at a heating rate of $3{ }^{\circ} \mathrm{C} \mathrm{min}^{-1}$ using a nitrogen flow rate of $100 \mathrm{ml} / \mathrm{min}$ to sweep up volatile products. For the coal, the final temperature of the TGA run was $1000^{\circ} \mathrm{C}$.

The coke yields for the coal G and its blends with LDPE were calculated as the mass percentage of residue after heat treatment at $1000^{\circ} \mathrm{C}$ at a heating rate of $3^{\circ} \mathrm{C} / \mathrm{min}$ by means thermogravimetric analysis.

The quality of the resultant cokes was assessed in terms of reactivity towards carbon dioxide at $1100{ }^{\circ} \mathrm{C}$ (CRI) and mechanical strength of the partially-gasified coke (CSR) using the Nippon Steel Corporation (NSC) method [24], according to ASTM D5341 standard procedure. Coke reactivity (CRI) was measured as the mass loss of coke after reaction with $\mathrm{CO}_{2}$ at $1100{ }^{\circ} \mathrm{C}$ for $2 \mathrm{~h}$ in a dried sample of $200 \mathrm{~g}$ with a particle size between 19 and $22.4 \mathrm{~mm}$. The partially-gasified coke was subjected to a mechanical treatment of 600 revolutions at $20 \mathrm{rpm}$. The amount of coke with a particle size larger than $9.5 \mathrm{~mm}$ after mechanical treatment is referred to as the CSR index. The limit values for a good quality coke are $\mathrm{CRI}<30$ and CSR $>60$ [25]. The lower the CRI index and the higher the CSR index, the better the coke quality is.

The pyrolysis of the coal and its blends with LDPE $(8 \mathrm{~g}$, $<0.212 \mathrm{~mm}$ ) was also carried out in a Gray King oven at three temperatures, 450,500 and $600{ }^{\circ} \mathrm{C}$ under the atmosphere of evolved gases, applying a heating rate of $5^{\circ} \mathrm{C} / \mathrm{min}$ and a soaking time of 5 min. The initials GK mean Gray-King pyrolysis and they are followed for the final temperature of the process (GK450, GK500 and GK600).

The design of the Gray King reactor is described in the standard procedure ISO502 modified by Suarez Ruiz et al. [26]. After leaving the reactor, the volatile products were condensed in a trap cooled by an ice salt bath (primary tar). The non-condensable fraction was removed from the reactor by means of an outlet tube. The solid carbon material (semicoke) was removed from the oven after cooling at room temperature.

The obtained semicokes were characterized by elemental analysis, Fourier transform infrared spectroscopy using the diffuse reflectance mode (DRIFT) and scanning electron microscopy (SEM). 
Percentage of $\mathrm{C}$ and $\mathrm{H}$ were determined by using a LECO CHN-2000 Macro according to ASTM D5373-02 standard procedure.

The spectra of the semicokes were performed using a Collector diffuse reflectance accessory placed in a Nicolet Magna IR560 spectrometer. A mercury cadmium telluride detector (MCT-A) operating at a sub ambient temperature was used. The particle size of the samples was $<0.212 \mathrm{~mm}$ and the spectra were recorded from 4000 to $650 \mathrm{~cm}^{-1}$ by 256 interferograms at a $4 \mathrm{~cm}^{-1}$ of resolution. An approximation-to-quantitative analysis was made by selected indices derived from the maximum intensity $(\mathrm{H})$ of different spectral bands $[5,9,27]$.

Gray King semicokes were analysed by scanning electron microscopy (SEM) to assess the incorporation of the plastic waste into the carbonaceous matrix. A scanning electron microscope Zeiss model DSM 942 equipped with an Energy Dispersive X-ray microanalyzer (EDX) detector OXFORD Link-Isis II was used. The secondary electron mode allows monitoring the topography of the semicokes and the backscattered electrons were used to discriminate between different phases in the samples. An accelerating voltage of $25 \mathrm{kV}$ was applied.

GC-FID-MS analysis of tars were performed on an Agilent Technologies Model 6890N equipped with two detector (flame ionization detector (FID) and mass spectrometer detector (MS) and two capillary columns HP-5MS ( $30 \mathrm{~m} \times 0.25 \mathrm{~mm}, 0.25 \mu \mathrm{m}$ film thickness). The temperature was programmed from 50 to $290{ }^{\circ} \mathrm{C}$ at a rate of $4{ }^{\circ} \mathrm{C} / \mathrm{min}$.

\section{Results and discussion}

A series of eight carbonizations was carried out on a semi-pilot scale (MWO15), adding to the G coal quantities of LDPE ranging from 1 to 30 wt.\% (concretely 1, 2, 3, 5, 7, 10, 20 and 30 wt.\%). The dry bulk density in the carbonization test was $690 \pm 30 \mathrm{~kg} /$ $\mathrm{m}^{3}$ on a dry basis. In this condition, a coking pressure higher than $10 \mathrm{kPa}$ is considered dangerous [14].

Depending on the quantity of LDPE added, different effects are detected on the coking pressure (Fig. 1). It can be observed that coking pressure increases for low LDPE addition levels (1-3 wt.\%) from $8 \mathrm{kPa}$ to $11-13 \mathrm{kPa}$. Nevertheless, the coking pressure for the coal-plastic mixture decreases considerably when high quantities of residue (5-30 wt.\%) are added to the coal. This produces an exponential decay of the coking pressure developed by the samples, being these values even lower than that of the $G$ coal and therefore safe values.

To understand the coking pressure mechanism it is necessary to take into account all the phenomena that influence the coking process, such as the development of coal plasticity, the volatile matter released in the plastic range of the coal and the swelling



Fig. 1. Coking pressure variation as a function of the amount of LDPE added. of the molten mass. These phenomena can be modified by the presence of LDPE. Therefore, the influence of the plastic waste on the different phenomena will be investigated.

To establish the effect of LDPE on coal plasticity, Gieseler tests were carried out. This method is used in the steel industry to determine the coal plastic range and the coal suitability for coking.

During the thermal treatment of the coal under an inert atmosphere, the coal particles start to soften at $412{ }^{\circ} \mathrm{C}$ (Table 2). They develop fluidity with increasing temperature, reaching a maximum value at $468{ }^{\circ} \mathrm{C}$ and, then fuse together into a semicoke at nearly $500^{\circ} \mathrm{C}$. These characteristic temperatures derived in a Gieseler plastometer define the physical changes during the plastic stage of a coal or a coal blend. The presence of LDPE does not practically affect these temperatures and, consequently, the plastic temperature range remains relatively constant.

Table 2 also shows the variation of Gieseler fluidity with the amount of LDPE added to the coal. At all percentages of LDPE addition, there is a reduction in Gieseler maximum fluidity. At low LDPE additions (1-3 wt.\%) a progressive reduction in plasticity occurs from 423 to $253 \mathrm{ddpm}$, which means a reduction from 12 to nearly $40 \%$ of the initial fluidity of the coal. An increase of LDPE up to $7 \mathrm{wt}$.\% causes a less pronounced decrease in fluidity from 253 to $214 \mathrm{ddpm}$, which represents a fluidity loss of $40 \%$ and nearly $50 \%$. With an addition of up to $10 \mathrm{wt} . \%$ LDPE, coal G maintains its fluidity inside or very close to the optimum range (200-1000 ddpm) defined for conventional charges [28-30].

The fluidity diminution has been reported in previous work $[4,9,11]$ and it can be attributed to the combined effect of the thermal stability of the polymers and the H-transfer from the coal to the plastic during co-pyrolysis.

In the case of bituminous coals there is no demonstrable correlation between fluidity and pressure generated in the coke oven, but it can be noticed that coals which have high fluidity (higher than $320 \mathrm{ddpm}$ ), do not develop dangerous coking pressure, regardless of rank [15,31]. In this case, the addition of LDPE modifies this tendency, showing that for additions of LDPE higher than $5 \mathrm{wt} . \%$, fluidity decreases along with the pressure developed. From these results it is clear that coal and plastic blends cannot be considered in the same way as bituminous coals, this can be due to the different fluidity of the components of the blend.

Coking pressure depends not only on the development of plasticity but also on the volatile matter released during the coking process. In this way, the thermal degradation of coal was investigated by thermogravimetric analysis (TGA). The rate of mass loss curves (DTG) during the carbonization of G coal and the LDPE at a heating rate of $3{ }^{\circ} \mathrm{C} / \mathrm{min}$ are shown in Fig. 2 .

The coal starts to release pyrolysis products at $235^{\circ} \mathrm{C}$ and this is in a temperature range wider than the plastic range $\left(235-869^{\circ} \mathrm{C}\right.$ from the coal vs $315-475^{\circ} \mathrm{C}$ from the LDPE). The decomposition of the molten polyolefins generates the formation of a multiplicity of aliphatic hydrocarbons of different molecular weights, ranging from 60 to $1500 \mathrm{Da}$ for the constituents of the oils and up to $4000 \mathrm{Da}$ for the waxes [32,33]. The highest release of hydrocarbons from LDPE takes place at $459^{\circ} \mathrm{C}$, which is lower than the temperature of the maximum volatile matter release of the coal $\left(475^{\circ} \mathrm{C}\right)$ (Fig. 2). Therefore, there is an increase of gaseous hydrocarbons derived from the polyolefins coinciding (i) with the formation of the plastic layer of the coking coal $\left(412-501{ }^{\circ} \mathrm{C}\right.$ accordingly to Gieseler test) and (ii) with the formation of organic substances from the thermal degradation of the coal, which helps to fluidize coal particles. This suggests an increase in pressure generated when hydrocarbons with high molecular weight cannot find the right way to escape from the oven. The retention of organic compounds formed from coal, helps to keep the coal in plastic state, acting as solvent agents. It is known that thermoplastics are dissolved by the action of organic solvents due to the penetration of solvent molecules 
Table 2

Specific parameters obtained by Gieseler plastometer test.

\begin{tabular}{llllll}
\hline Sample & Plastic $($ wt. $\%)$ & $F_{\max }(\mathrm{ddpm})$ & $T_{s}\left({ }^{\circ} \mathrm{C}\right)$ & $T_{f}\left({ }^{\circ} \mathrm{C}\right)$ & $T_{r}\left({ }^{\circ} \mathrm{C}\right)$ \\
\hline G & 0 & 423 & 412 & 468 & 501 \\
G1LDPE & 1 & 371 & 414 & 467 & 498 \\
G2LDPE & 2 & 313 & 415 & 468 & 84 \\
G3LDPE & 3 & 253 & 417 & 468 & 498 \\
G5LDPE & 5 & 233 & 414 & 465 & 501 \\
G7LDPE & 7 & 214 & 411 & 468 & 498 \\
G10LDPE & 10 & 157 & 410 & 467 & 501 \\
\hline
\end{tabular}

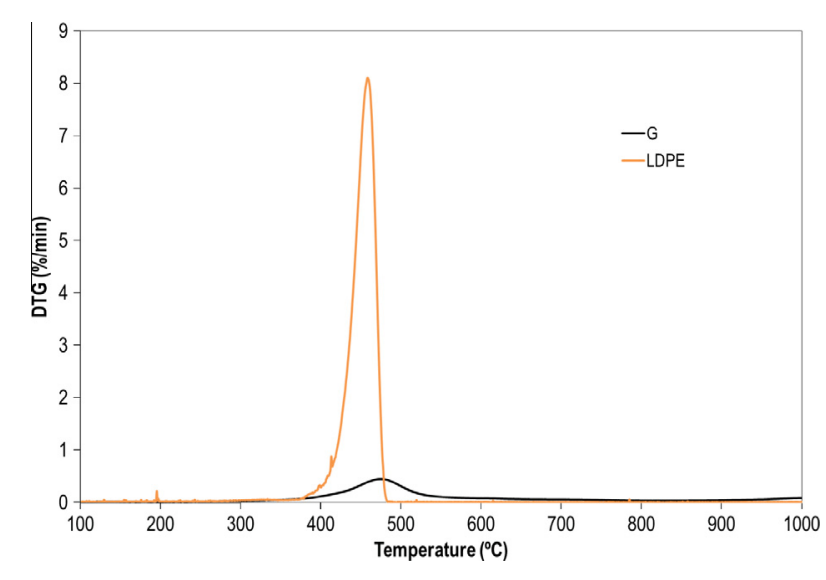

Fig. 2. DTG profiles of the coal $\mathrm{G}$ and LDPE at $3^{\circ} \mathrm{C} / \mathrm{min}$.

inside the macrostructure of the polymer, causing the separation between the different polymer chains due to the decrease of the van der Waals forces that keep them together and producing a slow swelling of the polymer molecule [34]. Therefore, if these organic compounds are good solvents for the polymer fragments or molten polymer, polymer-solvent interactions result in an increase of the swelling or expansion of geometric dimensions of the macromolecule causing a fluidity decrease, and low permeability of the plastic layer. Thus the generation of pressure in the furnace is higher than that produced in the absence of polymer. This could be the key to the increase in coking pressure for LDPE additions up to 3 wt.\%.

Nevertheless, it has been observed that with high quantities of LDPE there is a decrease in coking pressure, in spite of the highest presence of condensable and non-condensable pyrolytic products. In this case, the coal incorporates these quantities of hydrocarbons, due to the fact that there is a higher dispersion of the coal particles in the charge and a higher number of inter-particle pore spaces, which allow the LDPE products to flow. The amount of solvent compounds is not sufficient to create a plastic layer with suitable fluidity and to facilitate polymer/solvent interactions, finding the fragments of the polymer ways to leave the oven and suggesting a more independent carbonization of the two components of the blend. Therefore, high concentration of polymers produce a low fluidity, there is no excessive swelling of the plastic layer and the generated compounds can be compensated with the semicoke shrinkage.

Besides the effect of plastic addition on coking pressure, further experiments were necessary in order to study the effect of LDPE on coke quality. Therefore, the influence of plastic waste composition on coke quality was assessed in terms of their CRI and CSR (Fig. 3). In general, coke quality remains constant up to addition of $5 \mathrm{wt} . \%$; from this amount of LDPE the coke produced become more reactive (CRI index) while there is a deterioration in the mechanical strength (CSR index) which means an impair of coke quality.

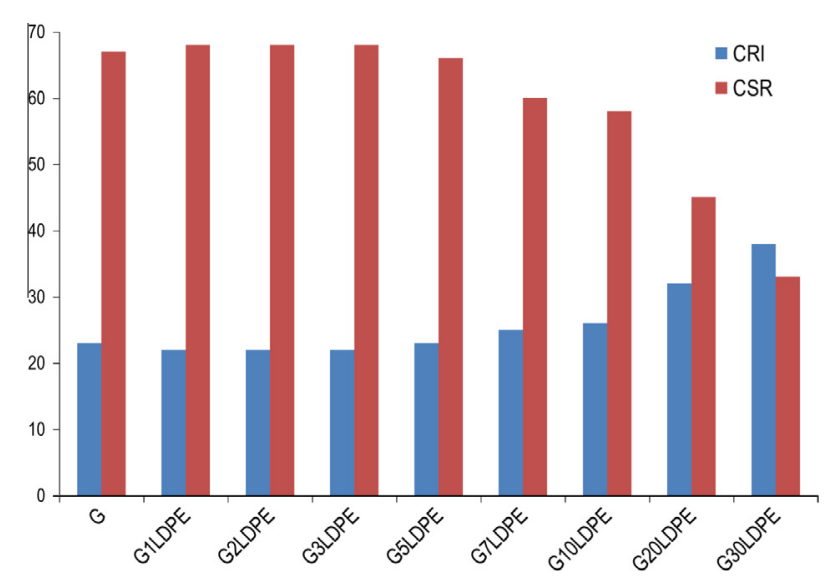

Fig. 3. CRI and CSR indices of the obtained cokes.

The amount of LDPE not only modify the CRI and CSR indices but also the coke yield, which decreases when the percentage of LDPE is $\geqslant 5$ wt.\% (Fig. 4).

This reflects that the percentage of polyolefins used is crucial not only for the development of coking pressure but also for coke quality. Additions higher than 5 wt.\% are not industrially viable, due to a great loss in coke productivity and deterioration of its physical and chemical characteristics. Therefore, in this study, additions higher than $5 \mathrm{wt} . \%$, were used only to emphasize the effect of the polyethylene on the coking pressure development.

\subsection{Coal/LDPE low temperature co-pyrolisis}

Co-pyrolysis experiments were carried out in order to: (i) confirm the incorporation of polyolefins or fragments of high

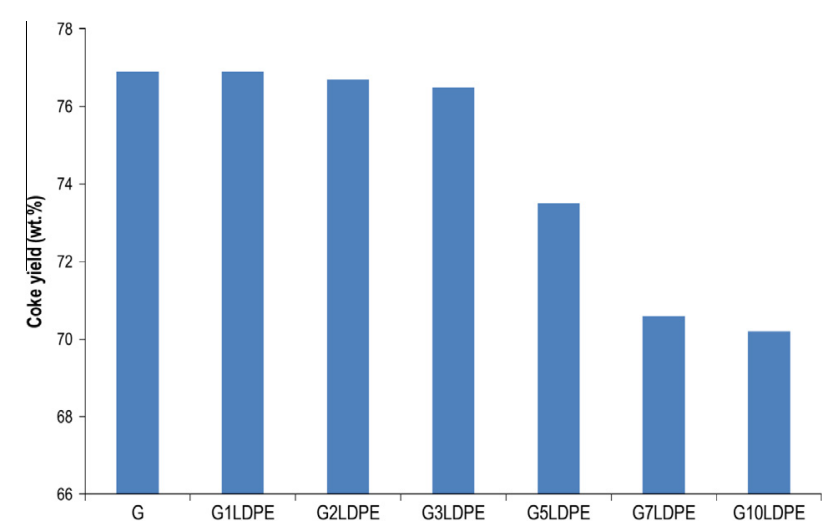

Fig. 4. Coke yield of the carbonizations (wt.\%) by means TGA at $3{ }^{\circ} \mathrm{C} / \mathrm{min}$. 
molecular weight from pyrolysis of LDPE in the carbonaceous matrix of the semicoke produced at $500{ }^{\circ} \mathrm{C}$, and (ii) elucidate how LDPE affects coking pressure.

Different blends of the coal and the residue were prepared $(2,5$, and $10 \mathrm{wt} . \%$ ) and Gray King tests were carried out at three different temperatures $\left(450,500\right.$ and $\left.600{ }^{\circ} \mathrm{C}\right)$. These temperatures were selected on the basis of the different phenomena occurring in coal carbonization. $450{ }^{\circ} \mathrm{C}$ is the approximate temperature at which maximum fluidity and maximum wall pressure in the coking process is achieved; $500{ }^{\circ} \mathrm{C}$ is the temperature at which fluid coal solidifies to form semicoke; and $600{ }^{\circ} \mathrm{C}$ is the initial step of the post plastic stage of the coking process.

The quantities of LDPE added were chosen on the basis of the effect of LDPE on fluidity reduction and coking pressure generation. The percentage of $2 \mathrm{wt} . \%$ addition influences the coking pressure to a greater degree, while at the same time the reduction in fluidity is moderate in the order of $100 \mathrm{ddpm}$ (nearly $25 \%$ of the initial fluidity). An addition of $5 \mathrm{wt} . \%$ LDPE produces a coking pressure slightly lower than that of the original coal and a fluidity reduction close to 50\%. An addition of $10 \mathrm{wt} . \%$ LDPE is associated with generating a negligible coking pressure in the semi-pilot oven and a reduction of the fluidity by nearly $63 \%$. The Gieseler fluidity of the coal and plastic blend remains at nearly $150 \mathrm{ddpm}$ (Table 2).

The mass balance at the three different temperatures at a relatively slow heating rate $\left(5^{\circ} \mathrm{C} / \mathrm{min}\right)$ is presented in Table 3 . At $450^{\circ} \mathrm{C}$, a low degree of decomposition takes place and all the blends show an almost identical product distribution.

At higher temperatures (500 and $600^{\circ} \mathrm{C}$ ) thermal cracking seems to promote the release of condensable products as primary tars at the expense of semicoke formation. Although a slow heating rate is applied, the removal of pyrolysis products from the hot zone in the reactor is favoured, reducing the residence time and the extent of secondary reactions. As a consequence, the amount of tar increases because the pyrolysis products condense before further reaction breaks down the high-molecular weight compounds into gaseous products. Linear relationships were found between the amount of LDPE added and the semicoke and tar yields, when the pyrolysis was carried out up to 500 and $600{ }^{\circ} \mathrm{C}$.

\subsection{Gray-King semicokes characterization}

The semicoke profiles obtained at different temperatures (450, 500 and $600{ }^{\circ} \mathrm{C}$ ) in the horizontal Gray King reactor are shown in Fig. 5. Depending on the carbonization temperature and the plastic percentage, the appearance of the semicokes obtained is varied. It is worthy to note that at $500{ }^{\circ} \mathrm{C}$ coal forms a hard, porous, well fused and highly swollen semicoke. However, none of the semicokes obtained at $500{ }^{\circ} \mathrm{C}$ from the mixture with LDPE show signs of having suffered a similar swelling during the co-carbonization.

The semicokes obtained at $600{ }^{\circ} \mathrm{C}$ from the mixtures with LDPE are more compact than the previous ones due to the contraction after plastic stage. At $2 \mathrm{wt} . \%$, the blend produces a hard and less-porous semicoke, which has increased length and width. It seems that a post-swelling takes place, which is known to be associated with a high viscosity melt and a release of volatile matter in the post-plastic stage. On the other hand, the semicoke obtained from the blend containing $10 \mathrm{wt} . \%$ LDPE is hard, very compact and moderately swollen but slightly shrunken in length (Fig. 5). These results agree with those obtained for the coking pressure (Fig. 1); as the G2LDPE semicoke is the one that presents the highest swelling and this blend develops higher coking pressure than the G10LDPE blend. It should be considered that the degree of contraction/expansion of the coal charge is an important factor for coking pressure [19]; higher contraction has been associated with lower coking pressure according to Koppers-INCAR test [20].

After the visual examination of the semicokes it is deduced that LDPE presence delays the onset of different phenomena that occur in the main stage of the coal; fluidity development, volatile matter release and swelling of the plastic layer. In addition LDPE modify the semicoke shrinkage degree.

LDPE addition not only modifies semicokes profiles, but also their elemental composition (Table 4). The semicokes obtained at $450{ }^{\circ} \mathrm{C}$ have a higher proportion of hydrogen, which is reflected in the lower atomic ratio $\mathrm{C} / \mathrm{H}$. This indicates that LDPE degradation is not completed, since LDPE thermal degradation ends at $500{ }^{\circ} \mathrm{C}$. This trend is clear when final carbonization temperature is 450 or $500{ }^{\circ} \mathrm{C}$, but at $600^{\circ} \mathrm{C}$ it does not occur. At this temperature, the semicokes produced from the blends have a higher atomic ratio $\mathrm{C} / \mathrm{H}$.

Semicokes DRIFT (Fig. 6) spectra show the typical bands present in coals. In general, semicokes at 450 and $500{ }^{\circ} \mathrm{C}$ show that the relative intensity of the $\mathrm{C}-\mathrm{H}$ aliphatic bands (2960, 2920 and $2855 \mathrm{~cm}^{-1}$ ) with respect to the absorption band at $3050 \mathrm{~cm}^{-1}$ (due to the $\mathrm{C}-\mathrm{H}$ bond in olefinic or aromatic systems) increases with the addition of LDPE and, decreases as the final temperature is higher. Therefore it suggests that LDPE or aliphatic nature fragments from pyrolysis are present, which also suggests partial degradation of the macromolecular structure of coal.

Table 5 shows the semi-quantitative variation of aromatic hydrogen (Har) with the amount of LDPE at the three selected temperatures. As the percentage of LDPE increases, the semicokes are less aromatic and therefore the proportion of aliphatic hydrogen is higher. This relationship is substantially linear with

Table 3

Yields of products obtained in the pyrolysis in a Gray-King oven.

\begin{tabular}{|c|c|c|c|c|}
\hline Sample & G & G2LDPE & G5LDPE & G10LDPE \\
\hline LDPE in the blend (wt.\%) & 0 & 2 & 5 & 10 \\
\hline $\begin{array}{l}\text { Pyrolysis temperature } 450^{\circ} \mathrm{C} \\
\text { Semicoke }(\mathrm{wt} . \% \mathrm{db}) \\
\text { Tar (wt.\% db) } \\
\text { Gas (wt.\% db) }\end{array}$ & $\begin{array}{l}97.9 \\
2.0 \\
0.1\end{array}$ & $\begin{array}{l}97.3 \\
2.1 \\
0.6\end{array}$ & $\begin{array}{l}97.0 \\
2.4 \\
0.6\end{array}$ & $\begin{array}{l}97.1 \\
2.6 \\
0.2\end{array}$ \\
\hline $\begin{array}{l}\text { Pyrolysis temperature } 500{ }^{\circ} \mathrm{C} \\
\text { Semicoke (wt.\% db) } \\
\text { Tar (wt.\% db) } \\
\text { Gas (wt.\% db) }\end{array}$ & $\begin{array}{l}91.6 \\
5.7 \\
2.7\end{array}$ & $\begin{array}{l}89.5 \\
7.6 \\
3.0\end{array}$ & $\begin{array}{l}87.1 \\
9.8 \\
3.1\end{array}$ & $\begin{array}{l}84.3 \\
12.8 \\
2.9\end{array}$ \\
\hline $\begin{array}{l}\text { Pyrolysis temperature } 600^{\circ} \mathrm{C} \\
\text { Semicoke (wt.\% db) } \\
\text { Tar (wt.\% db) } \\
\text { Gas (wt.\% db) }\end{array}$ & $\begin{array}{l}87.1 \\
6.7 \\
6.3\end{array}$ & $\begin{array}{l}85.1 \\
7.9 \\
6.9\end{array}$ & $\begin{array}{l}82.7 \\
10.8 \\
6.5\end{array}$ & $\begin{array}{l}78.5 \\
15.1 \\
6.3\end{array}$ \\
\hline
\end{tabular}




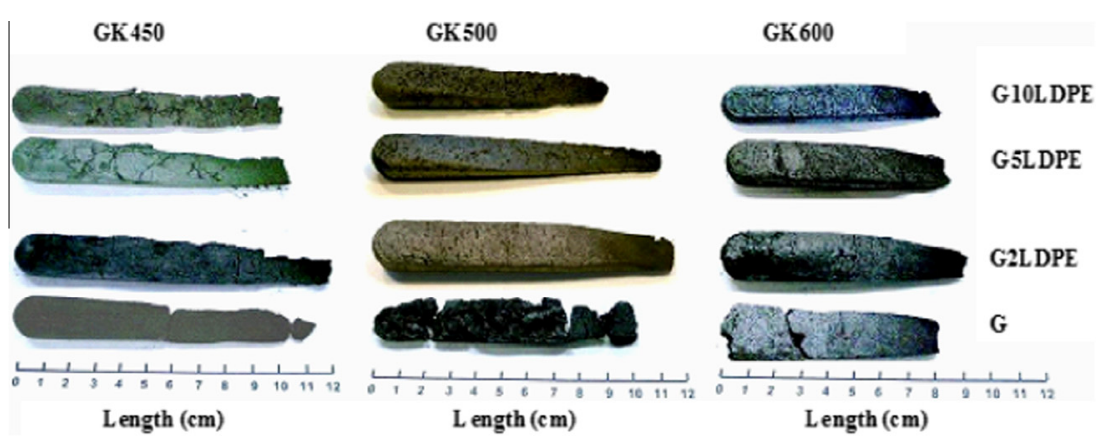

Fig. 5. Profiles of the semicokes obtained by Gray-King pyrolysis.

Table 4

Semicokes elemental composition.

\begin{tabular}{|c|c|c|c|c|}
\hline Sample & G & G2LDPE & G5LDPE & G10LDPE \\
\hline LDPE in the blend (wt.\%) & 0 & 2 & 5 & 10 \\
\hline $\begin{array}{l}\text { Pyrolysis temperature } 450^{\circ} \mathrm{C} \\
\mathrm{C} \text { (wt.\% daf) } \\
\mathrm{H} \text { (wt.\% daf) } \\
\mathrm{N} \text { (wt.\% daf) } \\
\mathrm{S} \text { (wt.\% daf) } \\
\mathrm{O} \text { (wt.\% daf) } \\
\text { Ash (wt.\% db) } \\
\text { C/H }\end{array}$ & $\begin{array}{l}88.8 \\
4.7 \\
1.7 \\
0.6 \\
4.2 \\
10.7 \\
1.56\end{array}$ & $\begin{array}{l}88.6 \\
4.8 \\
1.7 \\
0.6 \\
4.3 \\
9.6 \\
1.53\end{array}$ & $\begin{array}{l}89.0 \\
5.2 \\
1.7 \\
0.6 \\
3.5 \\
9.5 \\
1.44\end{array}$ & $\begin{array}{l}88.8 \\
5.6 \\
1.6 \\
0.6 \\
3.4 \\
9.7 \\
1.33\end{array}$ \\
\hline $\begin{array}{l}\text { Pyrolysis temperature } 500^{\circ} \mathrm{C} \\
\mathrm{C} \text { (wt.\% daf) } \\
\mathrm{H} \text { (wt.\% daf) } \\
\mathrm{N} \text { (wt.\% daf) } \\
\mathrm{S} \text { (wt.\% daf) } \\
\mathrm{O} \text { (wt.\% daf) } \\
\text { Ash (wt.\% db) } \\
\text { C/H }\end{array}$ & $\begin{array}{l}87.9 \\
4.3 \\
1.9 \\
0.6 \\
5.3 \\
10.0 \\
1.69\end{array}$ & $\begin{array}{l}88.0 \\
4.1 \\
1.9 \\
0.6 \\
5.4 \\
9.8 \\
1.79\end{array}$ & $\begin{array}{l}88.4 \\
4.5 \\
1.9 \\
0.6 \\
4.6 \\
9.4 \\
1.62\end{array}$ & $\begin{array}{l}87.4 \\
4.5 \\
1.7 \\
0.6 \\
5.8 \\
10.1 \\
1.60\end{array}$ \\
\hline $\begin{array}{l}\text { Pyrolysis temperature } 600{ }^{\circ} \mathrm{C} \\
\mathrm{C} \text { (wt.\% daf) } \\
\mathrm{H} \text { (wt.\% daf) } \\
\mathrm{N} \text { (wt.\% daf) } \\
\mathrm{S} \text { (wt.\% daf) } \\
\text { O (wt.\% daf) } \\
\text { Ash (wt.\% db) } \\
\text { C/H }\end{array}$ & $\begin{array}{l}90.0 \\
3.0 \\
1.8 \\
0.5 \\
4.7 \\
10.8 \\
2.54\end{array}$ & $\begin{array}{l}89.4 \\
2.9 \\
1.8 \\
0.6 \\
5.3 \\
10.7 \\
2.53\end{array}$ & $\begin{array}{l}89.7 \\
2.8 \\
1.8 \\
0.6 \\
5.1 \\
10.9 \\
2.63\end{array}$ & $\begin{array}{l}89.8 \\
2.9 \\
1.9 \\
0.6 \\
4.8 \\
10.5 \\
2.57\end{array}$ \\
\hline
\end{tabular}

the percentage of LDPE added when the final temperature is $450{ }^{\circ} \mathrm{C}$. At 500 and $600{ }^{\circ} \mathrm{C}$ this behavior does not occur. In this case a maximum value for the semi G2LDPE at $500{ }^{\circ} \mathrm{C}$ and G5LDPE at $600^{\circ} \mathrm{C}$ is detected. This is in agreement with the $\mathrm{C} / \mathrm{H}$ atomic ratio values calculated from the elemental composition.

Table 5 also shows the ratios of the bands areas assigned to the aromatic $\mathrm{C}-\mathrm{H}$ out of the plane bending modes (900$700 \mathrm{~cm}^{-1}$ ). At $450^{\circ} \mathrm{C}$, when the semicoke is more aromatic, a lower proportion of four adjacent hydrogen aromatic systems $\left(750 \mathrm{~cm}^{-1}\right)$ is observed. Therefore there is a higher substitution of the aromatic systems and/or less terminal benzene rings. The relative proportion of this type of aromatic hydrogen increases with the temperature. It suggests loss of substituents of the aromatic system and its condensation. Consequently, the semicokes at $600{ }^{\circ} \mathrm{C}$ are more aromatic and the degree of substitution of the aromatic systems or the number of terminal benzene rings is lower, increasing the systems with 2 and/or 3 adjacent hydrogen. The increase of 2 and/or 3 adjacent aromatic hydrogen varies almost linearly with the aromatic hydrogen content.

These results may point the presence of aliphatic chains from the LDPE, which have not reached a temperature high enough to decompose, or the presence of small aliphatic macromolecules that have been trapped in the carbon matrix.

To clarify this, samples were analysed by SEM. This technique supports the presence of two carbonaceous phases in the semicokes obtained at $500{ }^{\circ} \mathrm{C}$. One of these phases corresponds to LDPE distributed superficially in the matrix and in the pores (position B; Fig. 7). However at 450 and $600^{\circ} \mathrm{C}$ it is not possible to distinguish the two phases. In the semicokes at $450{ }^{\circ} \mathrm{C}$ there is a conglomerate of individual particles of coal, which have not started to melt together with small molten areas and possibly some molten plastic (position A; Fig. 7). In the semicokes at $600^{\circ} \mathrm{C}$, the LDPE macromolecules have degraded during the heat treatment, mainly in condensable aliphatic hydrocarbons, which become part of the tar.

\subsection{Gray King low-temperature tar characterization}

Soluble fraction in dichloromethane (DCM) of tar obtained from the Gray-king oven at 450,500 and $600{ }^{\circ} \mathrm{C}$ were analyzed by GC-FID-MS in order to obtain information about the composition of primary tars released in the carbonization process and on the distribution of the different families of compounds that 

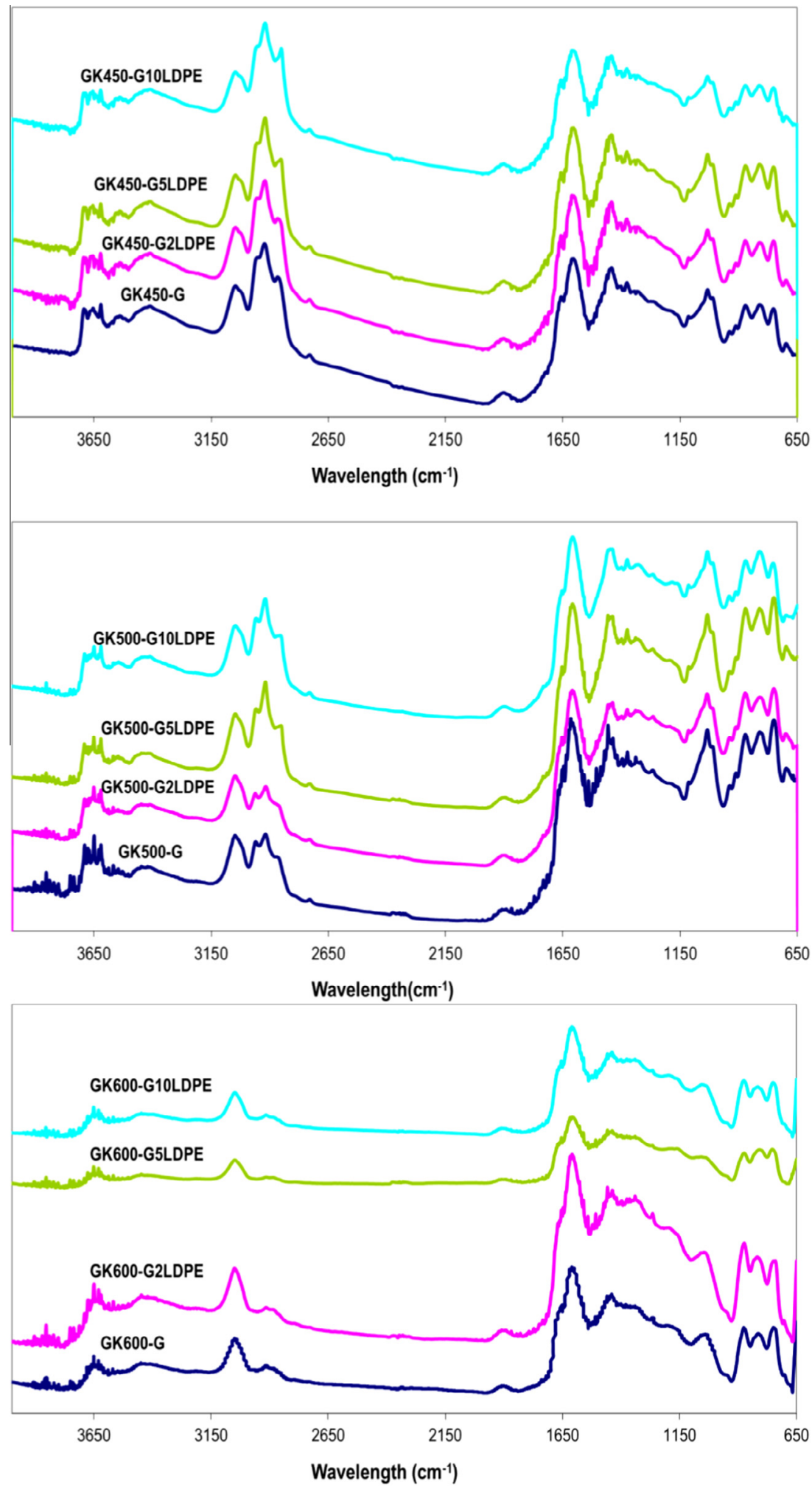

Fig. 6. Original DRIFT spectra of the semicokes.

may be relevant in the development of plasticity or coking pressure. In previous studies $[4,35]$ chromatograms of coal tar are divided into chromatographic areas, which are marked by the retention time of compounds with different boiling point and molecular size.

In this case, a division very suitably splits the chromatogram in three chromatographic regions: (i) R1 $(\leqslant \mathrm{C} 12)$ includes light volatile compounds having a retention time equal to or lower than n-dodecane (C12); i(i) R2 (C12-C19) includes compounds with a retention time between $\mathrm{C} 12$ and n-nonadecane (C19) and iii) R3 $(>\mathrm{C} 19)$ is composed of the heaviest compounds ranging from C19 to the end of the chromatogram.

Fig. 8 shows the chromatographic profiles of the different tars analyzed. Chromatographic profiles of tars obtained at $450{ }^{\circ} \mathrm{C}$ 
Table 5

Aromaticity index of the semicokes.

\begin{tabular}{llllll}
\hline Semicoke & Har & Hal & $\mathrm{H}_{870}$ & $\mathrm{H}_{810}$ & $\mathrm{H}_{750}$ \\
\hline GK450-G & 0.257 & 0.743 & 0.394 & 0.379 & 0.227 \\
GK450-G2LDPE & 0.250 & 0.750 & 0.401 & 0.362 & 0.237 \\
GK450-G5LDPE & 0.245 & 0.755 & 0.373 & 0.388 & 0.239 \\
GK450-G10LDPE & 0.234 & 0.766 & 0.385 & 0.371 & 0.244 \\
GK500-G & 0.373 & 0.627 & 0.382 & 0.357 & 0.261 \\
GK500-G2LDPE & 0.392 & 0.608 & 0.396 & 0.361 & 0.243 \\
GK500-G5LDPE & 0.321 & 0.679 & 0.371 & 0.379 & 0.250 \\
GK500-G10LDPE & 0.319 & 0.681 & 0.367 & 0.404 & 0.229 \\
GK600-G & 0.688 & 0.312 & 0.342 & 0.378 & 0.281 \\
GK600-G2LDPE & 0.703 & 0.297 & 0.346 & 0.383 & 0.271 \\
GK600-G5LDPE & 0.776 & 0.224 & 0.302 & 0.408 & 0.290 \\
GK600-G10LDPE & 0.734 & 0.266 & 0.330 & 0.397 & 0.273 \\
\hline
\end{tabular}

Har and Hal: aromatic and aliphatic hydrogen ratio respectively. $\mathrm{H}_{870}, \mathrm{H}_{810}$ and $\mathrm{H}_{750}$ : areas ratio of the bands allocated to an isolated hydrogen in an aromatic system $\left(870 \mathrm{~cm}^{-1}\right), 2$ and 3 hydrogens $\left(810 \mathrm{~cm}^{-1}\right)$ and four hydrogens $\left(750 \mathrm{~cm}^{-1}\right)$ relating to the spectral region area $950-725 \mathrm{~cm}^{-1}$.

were similar. This similarity is less pronounced when the amount of LDPE added is increased. At this temperature tar composition comes from the thermal decomposition of coal. However, at 500 and $600{ }^{\circ} \mathrm{C}$ it can be seen that the chromatographic profiles of $\mathrm{G}$ coal tars and those from blends with LDPE, differ substantially. These last samples display clearly distinguishable chromatographic peaks corresponding to the series of n-alkanes (C8-C37) from the pyrolysis of LDPE. Chromatograms of tars produced from blends with LDPE reveal the presence of double peaks of different intensity. Less intense peaks are due to olefin compounds with a terminal double bond and the same number of carbon atoms than the corresponding n-alkane [4].

Other types of compounds present in the tar come mostly from the decomposition of coal, such as phenolic compounds, light aromatic hydrocarbons substituted by alkyl groups and polycyclic aromatic hydrocarbons (HAP).

Considering chromatographic regions defined, Table 6 gives their distribution in percentage terms, assuming that $100 \%$ of the tar is eluted. In the tars obtained at $450^{\circ} \mathrm{C}$, the region corresponding to the lightest hydrocarbons (R1) decreases with the presence of plastic, with a consequent increase of the heaviest compounds (R3).

By increasing the carbonization temperature $\left(500\right.$ and $\left.600{ }^{\circ} \mathrm{C}\right)$ the amount of the heaviest hydrocarbon increases with the addition of LDPE, as a result of the thermal degradation of the LDPE polymer chain. At $500^{\circ} \mathrm{C}$ the distribution of the three fractions for the $\operatorname{tar} G(R 1, R 2$ and R3) is similar (around 30\% and 35\%). However, the addition of LDPE considerably decreases low and medium-volatile compounds ( $\mathrm{R} 1$ and $\mathrm{R} 2$ regions). An increase of the temperature to $600{ }^{\circ} \mathrm{C}$ causes no significant modification in the distribution of these fractions.
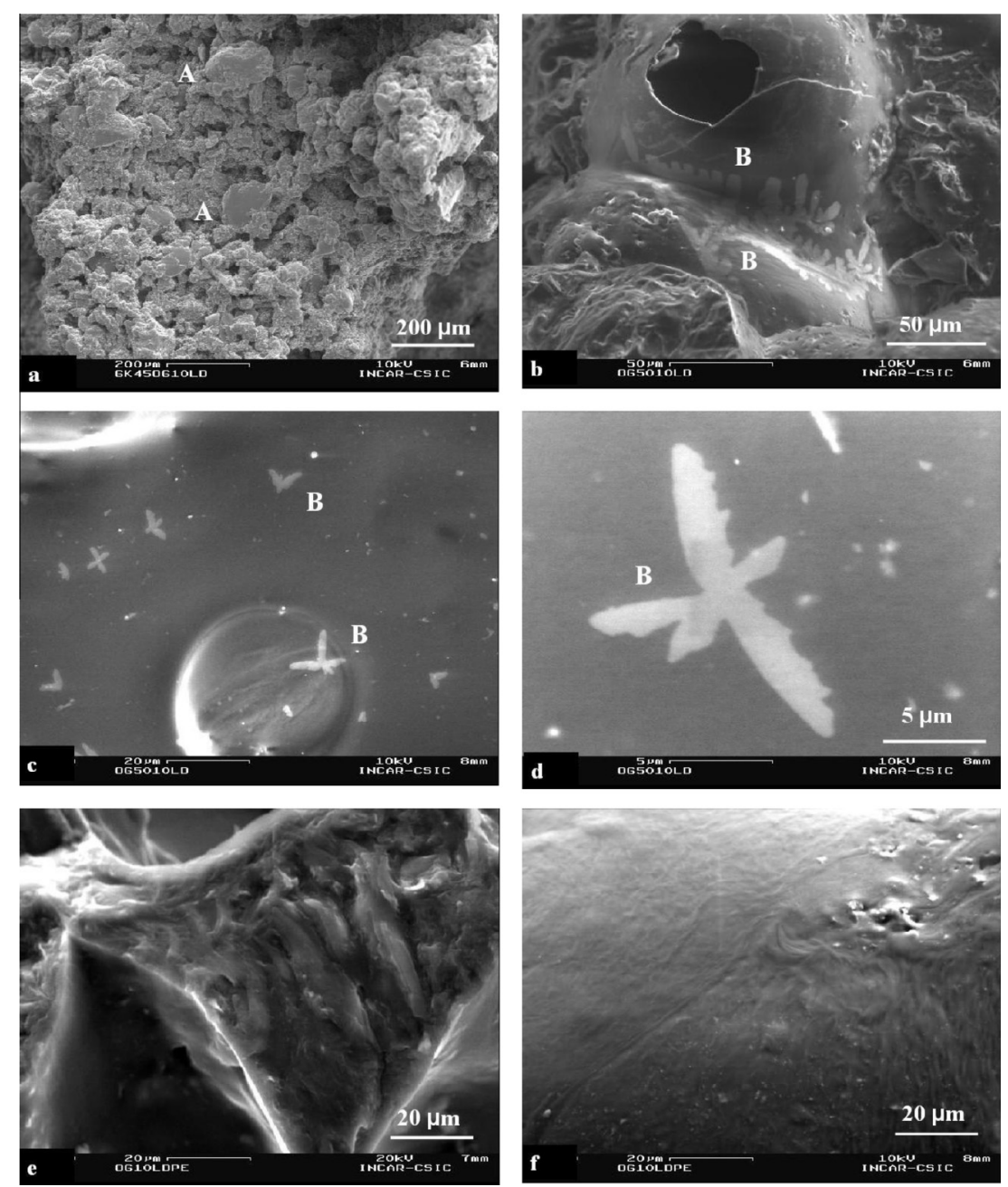

Fig. 7. SEM micrograph of the semicokes from coal G and its blend with 10 wt. $\%$ LDPE at $450{ }^{\circ} \mathrm{C}(\mathrm{a}), 500{ }^{\circ} \mathrm{C}(\mathrm{b}-\mathrm{d})$ and $600{ }^{\circ} \mathrm{C}(\mathrm{e}$ and f). 



Fig. 8. Chromatographic profiles of the tars at 450,500 and $600{ }^{\circ} \mathrm{C}$.

Also, it is interesting to note that by increasing LDPE from 5 to $10 \mathrm{wt} . \%$, no significant variations in the distribution of these fractions were observed, although high tar yield was obtained (Table 3 ).

Comparing tars produced at 500 and $600{ }^{\circ} \mathrm{C}$ from blends of coal and LDPE, it is clear that the compound distribution is different to tar products from the addition of $2 \mathrm{wt} . \%$. This tar shows a high proportion of light compounds (R2) at the expense of the heavier fraction (R3), which can be due to retention of the heavier compounds during co-carbonization and consequently can increase the pressure generated in the process. 
Table 6

Distribution of the products in the three chromatographic regions.

\begin{tabular}{lllll}
\hline Sample & \%Plastic & $\mathrm{R} 1\left(\leqslant \mathrm{C}_{12}\right)$ & $\mathrm{R} 2\left(\mathrm{C}_{12}-\mathrm{C}_{19}\right)$ & $\mathrm{R} 3\left(>\mathrm{C}_{19}\right)$ \\
\hline GK450-G & 0 & 34.6 & 42.0 & 23.4 \\
GK450-G2LDPE & 2 & 27.1 & 40.9 & 32.0 \\
GK450-G5LDPE & 5 & 19.2 & 40.2 & 40.6 \\
GK450-G10LDPE & 10 & 14.5 & 41.7 & 43.8 \\
GK500-G & 0 & 31.7 & 35.3 & 33.0 \\
GK500-G2LDPE & 2 & 12.5 & 29.3 & 58.2 \\
GK500-G5LDPE & 5 & 12.7 & 21.7 & 65.6 \\
GK500-G10LDPE & 10 & 13.8 & 19.4 & 66.8 \\
GK600-G & 0 & 27.1 & 39.5 & 33.4 \\
GK600-G2LDPE & 2 & 14.0 & 27.4 & 58.5 \\
GK600-G5LDPE & 5 & 14.8 & 22.9 & 62.3 \\
GK600-G10LDPE & 10 & 15.5 & 20.6 & 63.9 \\
\hline
\end{tabular}

\section{Conclusions}

The addition of LDPE to a bituminous coal modifies the different phenomena of the coking process such as coal fluidity development, loss of volatile matter and swelling of the fused mass. Depending on the amount of LDPE added to a coking coal, a different effect on coking pressure can be observed. The pressure data obtained confirm previous results $[10,11]$. The addition of LDPE in small amounts (1-3\%) greatly increases coking pressure, reaching levels that are too high for coke oven safety. Conversely, additions of high amounts of polyolefins (5-10\%) reduce the pressure generated during the coking process; reaching values lower than that of the safe coal G. These results agree with those obtained from the visual examination of the Gray-King semicokes.

Although the explanation for this is difficult to establish, it is suggested that, as in conventional charge, a different combination of effects may be taking place. The high viscosity of the melted LDPE and its decomposition products, especially waxes (long hydrocarbons chain), make it more difficult for the primary pyrolysis products to be transported through the coal bed. Thus, a certain proportion of these may be captured by the fluid mass of coal, thereby decreasing fluidity. In addition, the plastic layer will be less homogeneous with some local areas containing LDPE randomly distributed in the matrix which progress at different rates during carbonization. The evolution of gas from the mass of the coal and LDPE results in further dilatation, giving rise to an increase in coking pressure. However higher amounts of LDPE reduce coking pressure. This result is somewhat surprising because the effect of polyethylene should be more pronounced (i.e. more condensable and non-condensable gases, a greater number of local areas containing melted LDPE). The reason that this is not so may be due to a reduction in the bulk density of the charge and the better permeability to the migration of oil components, which suggest a lower interaction between the coal and the LDPE.

From the profiles of the semicokes obtained by Gray-King pyrolysis it can be deduced that there is a delay in the LDPE degradation. This fact is confirmed by de data provided by DRIFT and SEM. These tests reveal the presence of LDPE at $500^{\circ} \mathrm{C}$, when it should be already degraded, as indicates the thermogravimetric analysis. In addition, tar analysis reveals the retention of the heavier compounds in the semicokes with $2 \mathrm{wt} . \%$ of LDPE. This fact may be the reason that causes the increase of the coking pressure generated.

Finally, the percentage of polyolefins added to the blend is crucial for the coking process, since this percentage affects not only the fluidity development, volatile matter release and swelling of the plastic layer, but also the coke quality and productivity. Therefore additions higher than $5 \mathrm{wt}$.\% are not recommended in order to avoid negative effects on the coke quality and coke yield.

\section{Acknowledgments}

The authors thank the Spanish Ministry of Education and Science for financial support (Research Project CTM2004-03254). We also thank Abornasa and Arcelor for participating in the project.

\section{References}

[1] Kato K, Nomura S and Hematsu H. Development of waste plastic recycling process using coke ovens. In: Iron making conference proceedings, iron and steel society. Warrendale, EEUU; 2000, vol. 61, p. 633-42.

[2] NSC-NKK, NSC and NKK to expand plastic recycling. Iron and Steelmaker. January; 2000. p. 17.

[3] Diez MA, Alvarez R, Canga CS, Barriocanal C, Gayo F, Dominguez A. Cocarbonization of coal with LDPE and HDPE plastic waste at three different scales. Eurocarbon 2000;II:717-8.

[4] Dominguez A, Blanco CG, Barriocanal C, Alvarez R, Diez MA. Gas chromatography study of the volatile products from co-pyrolysis of coal and polyethylene wastes. J Chromatogr 2001;918:135-44.

[5] Diez MA, Barriocanal C, Alvarez R. Plastics wastes a modifiers of the thermoplasticity of coal. Energy Fuels 2005;19:2304-16.

[6] Nomura S, Kato K, Nakagawa T, Komaki I. The effect of plastic addition on coal caking properties during carbonization. Fuel 2003;82:1775-82.

[7] Sakurovs R. Interactions between coking coals and plastics during co-pyrolysis. Fuel 2003;82:1911-6.

[8] Castro Diaz M, Edecki L, Steel KM, Patrick JW, Snape CE. Determination of the effects caused by different polymers on coal fluidity during carbonization using high-temperature ${ }^{1} \mathrm{H}$ NMR and rheometry. Energy Fuels 2008;22:471-9.

[9] Vivero L, Barriocanal C, Alvarez R, Diez MA. Effects of plastic wastes on coal pyrolysis behaviour and the structure of semicokes. J Anal Appl Pyrol 2005;74:327-36.

[10] Diez MA, Alvarez R, Barriocanal C, Melendi S. Possibilities of the coking process for recycling plastic wastes. Eurocoke Summit; 2007 [Intertech-Pira].

[11] Melendi S, Diez MA, Alvarez R, Barriocanal C. Relevance of the composition of municipal plastic wastes for metallurgical coke production. Fuel 2011;90:1431-8.

[12] Nomura S, Thomas KM. Some aspects of the generation of coking pressure during coal carbonization. Fuel 1996;75:801-8.

[13] Nomura S, Arima T. The effect of volume change of coal during carbonization in the direction of coke oven width on the internal gas pressure in the plastic layer. Fuel 2001;80:1307-15.

[14] Casal MD, Diaz-Faes E, Alvarez R, Diez MA, Barriocanal C. Influence of the permeability of the coal plastic layer on coking pressure. Fuel 2006;85:281-8.

[15] Barriocanal C, Patrick JW, Walker A. The laboratory identification of dangerously coking coals. Fuel 1997;77:881-4.

[16] Nomura S, Mahoney M, Fukuda K, Kato K, Le Bas A, McGuire S. The mechanism of coking pressure generation I: effect of high volatile matter coking coal, semi-anthracite and coke breeze on coking pressure and plastic coal layer permeability. Fuel 2010;89:1549-56.

[17] Mahoney M, Nomura S, Fukuda K, Kato K, Le Bas A, Jenkins DR, et al. The mechanism of coking pressure generation II: effect of high volatile matter coking coal, semi-anthracite and coke breeze on coking pressure and contraction. Fuel 2010;89:1557-65.

[18] Hanson S, Steel KM, Snape CE, Patrick JW. The possible role of fissure formation in the prevention of coking pressure development. Fuel 2006;85:19-24.

[19] Duffy JJ, Castro Diaz M, Snape CE, Steel KM, Mahoney MR. Understanding the mechanisms of coking pressure: relationship to pore structure. Fuel 2007;86:2167-78.

[20] Casal MD, Barriocanal C, Diez MA, Alvarez R. Influence of porosity and fissuring on coking pressure generation. Fuel 2008;87:2437-43.

[21] Diez MA, Alvarez R, Melendi S, Barriocanal C. Feedstock recycling of plastic wastes/oil mixtures in coke making. Fuel 2009;88:1937-44.

[22] Melendi S, Diez MA, Alvarez R, Barriocanal C. Plastic wastes, lube oils and carbochemical products as secondary feedstocks for blast-furnace coke production. Fuel 2011;92:471-8.

[23] Diez MA, Alvarez R, Melendi S, Barriocanal C. Feedstock recycling of plastic wastes in coke making. Coke Chem 2009;52:464-6.

[24] British Carbonization Research Association, (B.C.R.A.). The evaluation of the nippon steel corporation reactivity and post-reaction strength test for coke, carbonization research report 91. UK: Chesterfield, 19808. p. 50.

[25] Leonard DC, Bonte L, Dufour A, Ferstl A, Raipala K, Schmole P, Schoone, P, Verduras JL, Willmers RR. Coke quality requirements of European blast furnace engineers (Joint EBFC-Paper) 1996. In: Proc 3rd Eur Coke making Cong. Gent, Belgium: CRMVDEh, p. 1-10

[26] Suarez-Ruiz I, Martinez L, Bertrand Ph, Prado JG, Disnar JR. Influence of rock particle size on the artificial thermal evolution of kerogen. A petrographic and geochemical study. Int J Coal Geol 1994;25:47-64.

[27] Kister J, Pieri N, Alvarez R, Diez MA, Pis JJ. Effects of preheating and oxidation on two bituminous coals assessed by synchronous UV fluorescence and FTIR spectroscopy. Energy Fuels 1996;10:948-57. 
[28] Loison R, Foch P, Boyer A. Coke quality and production. London: Butterwoth 1989.

[29] Okuyama Y, Miyazu T, Sugimura H, Kumagai M. Prediction of the coking property of coal by microscopic analysis. J. Fuel Soc Jpn 1970;49(522):736-43.

[30] Miyazu T. The evolution and design of blends using many kinds of coals for cokemaking. Cong Dusseldorf; 1974. p. 1.2.2.1.

[31] Diaz-Faes M. Elvira Estudio a diferentes escalas del empuje de carbones coquizables y de la calidad del coque. Tesis doctoral; 2010, Universidad de Oviedo.
[32] Williams EA, Williams PT. Analysis of products derived from the fast pyrolysis of plastic waste. J Anal Appl Pyrol 1997;40(41):347-63.

[33] Williams EA, Williams PT. The pyrolysis of individual plastics and a plastic mixture in a fixed bed reactor. J Chem Tech Biotechnol 1997;70:9-20.

[34] Miller-Chou BA, Koenig JL. A review of polymer dissolution. Prog Polym Sci 2003:28:1223-70.

[35] Casal MD, Diez MA, Barriocanal C. Suitability of Gray-King pyrolysis to evaluate coking pressure. J Anal Appl Pyrol 2007;79:161-8. 